\title{
Validation of a general subjective well-being factor using Classical Test Theory
}

\author{
Ali Al Nima ${ }^{\text {Corresp., 1, }}{ }^{\text {, }}$ Kevin M Cloninger ${ }^{1,3}$, Franco Lucchese ${ }^{4}$, Sverker Sikström $^{5}$, Danilo Garcia ${ }^{\text {Corresp. } 1,2,6}$ \\ 1 Blekinge Center of Competence, Region Blekinge, Karlskrona, Sweden \\ 2 Department of Psychology, University of Gothenburg, Gothenburg, Sweden \\ 3 Anthropedia Foundation, St. Louis, Missouri, United States of America \\ 4 Department of Dynamic and Clinical Psychology, University of Rome "La Sapienza", Rome, Italy \\ 5 Depeartment of Psychology, Lund University, Lund, Sweden \\ 6 Department of Behavioral Science and Learning, Linköping University, Linköping, Sweden \\ Corresponding Authors: Ali Al Nima, Danilo Garcia \\ Email address: alinor_1979@yahoo.co.uk, danilo.garcia@icloud.com
}

\section{Background}

Subjective Well-Being (SWB) is usually conceptualized in terms of an affective (i.e., judgements of biological emotional reactions and experiences) and a cognitive component (i.e., judgements of life satisfaction in relation to a psychological self-imposed ideal). Recently, researchers have suggested that judgements of harmony in life can replace or at least complement the cognitive component of SWB. Here, however, we go beyond that suggestion and propose that harmony in life should be seen as SWB's social component since it is the sense of balance between the individual and the world around her-a process that comprises acceptance, adaptation, and balance. By adding judgements of one's social interactions (i.e., harmony in life) to judgments of one's life satisfaction (psycho) and judgements of one's emotional reactions (bio), we propose a tentatively biopsychosocial model of SWB. As a first step, we used different factorial models in order to determine if both a general factor and specific sub-factors contribute to the biopsychosocial model of SWB.

\section{Method}

A total of 527 participants responded to the Positive Affect Negative Affect Schedule (PANAS; 20 items), the Satisfaction with Life Scale (SWLS; five items), and the Harmony in life Scale (HILS; five items). We conducted exploratory and confirmatory factor analyses to validate the biopsychosocial model of subjective well-being and a general factor (SWBS).

\section{Results}

The 20 PANAS items reflected a mixture of general latent structure saturation and specific latent structure saturation, but contributed to their respective specific latent factor (PA: 25\%; NA: 32\%) more than to the general latent SWBS factor (positive affect: $25 \%$; negative affect: $32 \%$ ). The five SWLS items contributed to a larger degree to the general SWBS factor (72\%) than to life satisfaction itself $(22 \%)$, while the five HILS items contributed to even a larger degree to the general SWBS factor (98\%) than to harmony in life (0\%). The bifactor model was the best model compared with all other models we tested $\left(\chi^{2}=1660.78, d f=375, p<.001\right.$; Satorra Bentler $\chi^{2}=1265.80, d f=375, p<.001 ; C F I=.92$; TuckerLevis ind in 
variance in the model, while specific SWBS components together explained $15 \%$ of the total variance.

\section{Conclusion}

Our study suggests SWB as a general factor in a multidimensional biopsychosocial model. Indeed, as much as $64 \%$ of the variance of SWB was explained by this general factor. The SWB components, however, contributed to a different degree to each corresponding factor in the model. For instance, while the affective and cognitive components seem to be their own constructs and also part of the general SWB factor, the social component tested here contributed $0 \%$ to its own variance but $98 \%$ to the general factor. 


\section{Under review in PeerJ}

2 Please do not quote or cite without permission

3

4

5

6

7

8

9 8

\section{Validation of a General Subjective Well-Being Factor using Classical Test Theory}

Ali Al Nima ${ }^{1,2 *}$, Kevin M. Cloninger ${ }^{1,3}$, Franco Lucchese ${ }^{4}$, Sverker Sikström ${ }^{5}$ Danilo Garcia ${ }^{1,2,6 *}$ ${ }^{1}$ Blekinge Center of Competence, Region Blekinge, Karlskrona, Sweden ${ }^{2}$ Depeartment of Psychology, University of Gothenburg, Gothenburg, Sweden ${ }^{3}$ Anthropedia Foundation, St. Louis, Missouri, USA

${ }^{4}$ Department of Dynamic and Clinical Psychology, University of Rome "La Sapienza”, Rome, Italy ${ }^{5}$ Depeartment of Psychology, Lund University, Lund, Sweden ${ }^{6}$ Department of Behavioral Sciences and Learning, Linköping University, Linköping, Sweden 


\section{Abstract}

28

29

30

31

32

\section{Background}

Subjective Well-Being (SWB) is usually conceptualized in terms of an affective (i.e., judgements of biological emotional reactions and experiences) and a cognitive component (i.e., judgements of life satisfaction in relation to a psychological self-imposed ideal). Recently, researchers have suggested that judgements of harmony in life can replace or at least complement the cognitive component of SWB. Here, however, we go beyond that suggestion and propose that harmony in life should be seen as SWB's social component since it is the sense of balance between the individual and the world around her-a process that comprises acceptance, adaptation, and balance. By adding judgements of one's social interactions (i.e., harmony in life) to judgments of one's life satisfaction (psycho) and judgements of one's emotional reactions (bio), we propose a tentatively biopsychosocial model of SWB. As a first step, we used different factorial models in order to determine if both a general factor and specific sub-factors contribute to the biopsychosocial model of SWB.

\section{Method}

A total of 527 participants responded to the Positive Affect Negative Affect Schedule (PANAS; 20 items), the Satisfaction with Life Scale (SWLS; five items), and the Harmony in life Scale (HILS; five items). We conducted exploratory and confirmatory factor analyses to validate the biopsychosocial model of subjective well-being and a general factor (SWBS).

\section{Results}

The 20 PANAS items reflected a mixture of general latent structure saturation and specific latent structure saturation, but contributed to their respective specific latent factor (PA: 25\%; NA: 32\%) more than to the general latent SWBS factor (positive affect: $25 \%$; negative affect: $32 \%$ ). The five SWLS items contributed to a larger degree to the general SWBS factor $(72 \%)$ than to life satisfaction itself $(22 \%)$, while the five HILS items contributed to even a larger degree to the general SWBS factor (98\%) than to harmony in life $(0 \%)$. The bifactor model was the best model compared with all other models we tested $\left(\chi^{2}=1660.78, d f=375, p<.001\right.$; Satorra Bentler $\chi^{2}=1265.80, d f=375, p<.001 ; C F I=.92 ;$ Tucker-Lewis Index $=.91 ;$ RMSEA $=.067$. This model of a general SWBS factor explained about $64 \%$ of the total variance in the model, while specific SWBS components together explained $15 \%$ of the total variance.

\section{Conclusion}

Our study suggests SWB as a general factor in a multidimensional biopsychosocial model. Indeed, as much as $64 \%$ of the variance of SWB was explained by this general factor. The SWB components, however, contributed to a different degree to each corresponding factor in the model. For instance, while the affective and cognitive components seem to be their own constructs and also part of the general SWB factor, the social component tested here contributed $0 \%$ to its own variance but $98 \%$ to the general factor. 
68 Keywords: Bifactor Analysis, Biopsychosocial Model of Subjective Well-Being, Harmony in Life 69 Scale, Positive Affect Negative Affect Schedule, Satisfaction with Life Scale, Subjective Well70 Being.

71

72

73

74

75

76

77

"The whole is greater than the sum of its parts."

Aristotle

"I... a universe of atoms, an atom in the universe."

Richard P. Feyman

\section{Introduction}

For over 35 years, subjective well-being has been conceptualized as a dyad consisting of an affective and a cognitive component/part (Diener, 1984). The affective component is often conceptualized as one's evaluations of biological positive and negative emotional experiences in daily life, while the cognitive component is often conceptualized as evaluations of one's life as a whole in relation to a psychological self-imposed ideal-together, the frequent experience of positive affect, the infrequent experience of negative affect, and being satisfied with life is the way researcher operationalize high subjective well-being (Diener, Emmons, Larsen \& Griffin, 1985; Diener, Lucas, Schimmack \& Helliwell, 2009; Cloninger, 2004; Lyubomirsky, 2008; Peterson \& Seligman, 2004). In this configuration, subjective well-being is considered as one of the best available proxies for a broader, more canonical form of well-being (Diener, Lucas, \& Oishi, 2018) and strongly associated with personality ${ }^{1}$ (Eid \& Larsen, 2008). Indeed, well-being depends on a person's ability to achieve homeostasis or to adapt to circumstances outside the self and to characteristics within the person (Cloninger, 2004). In this context, some researchers suggest that

\footnotetext{
${ }^{1}$ Personality can be defined as the "dynamic organization within the individual of the psychobiological systems by which the person both shapes and adapts uniquely to an ever-changing internal and external environment" (Cloninger, 2012).
} 
93 subjective well-being needs to also be understood as inner harmony (e.g., Delle Fave, Brdar,

94 Wissing, Araujo, Castro Solano, et al., 2016; Delle Fave, Brdar, Freire, Vella-Brodrick, \& Wissing,

95 2011), while others suggest that harmony in life is a complement to or even a supplement of the

96 cognitive component of subjective well-being - life satisfaction (Kjell, Daukantaite, Hefferon \&

97 Sikström, 2016). We agree in the fact that this component is extremely important for our

98 understanding of subjective well-being, since harmony in life is the expression of a process of

99 acceptance and adaptation in order to achieve inner peace and balance or homeostasis within and

100 outside the self. We argue, however, that harmony in life is distinct to life satisfaction, especially

101 in light of a biopsychosocial perspective on subjective well-being.

The biopsychosocial model is a scientific model that refers to a dynamic and complex

interaction of physiological, psychological, and social factors that can both result in and contribute

to health (Cloninger, 2004; Engel, 1977, 1980). Such a model covers all the parts that compose a

human being (i.e., body, mind, and psyche $^{2}$ ), it corresponds to a ternary model of human

awareness: the self, others, and something greater than the self, such as, nature, God or the universe

(Cloninger, 2014), and corresponds also to the concept of health as a state of physical, mental, and

social well-being (WHO, 2001). Naturally, we propose that the evaluation of positive and negative

affect is the biological part of subjective well-being, since emotions are derived from our nervous

110 system and our temperament, a part of personality with a strong genetic factor that is relatively

111 stable over the life span (Cloninger, 2004; Josefsson, Jokela, Cloninger, Hintsanen, Salo et al.,

112 2013; Zwir et al., 2018ab, 2019). In contrast, although also relatively stable, the cognitive

113 component of subjective well-being, life satisfaction, seems to fluctuate with time and to be

114 influenced by changes in life circumstances (Fujita \& Diener, 2005), such as, divorce and losing

\footnotetext{
${ }^{2}$ The Greek word psyche found in psychology and psychiatry stands for "life, soul, or spirit,", which is distinct from soma, which refers to the "body" (Cloninger, 2004; see also Cloninger \& Cloninger, 2011ab; Cloninger, Salloum, \& Mezzich, 2012).
} 
115 one's life partner (e.g., Lucas, Clark, Georgellis \& Diener, 2003). Since life satisfaction is an

116 evaluation of one's life in relation to a psychological self-imposed ideal, we propose that it should

117 be understood as the psychological part of a biopsychosocial model of subjective well-being. As a

118 result of this suggestion, the question is the how harmony in life is different from life satisfaction?

119 Firstly, as a concept, harmony is related to the sense of balance and flexibility that a person

120 experiences in relation to her life and the world around her (cf. Li, 2008). Ergo, conceptually, it

121 involves transcendence of the self and comprises notions of a person being in balance, in

122 agreement, or striving for equilibrium with the environment (e.g., surroundings, other people,

123 family, friends, nature, and her own existence). Secondly, psychometrically, despite a strong

124 correlation between life satisfaction and harmony in life $(r=.76)$, two-factor model solutions,

125 rather than single factor models, seem considerably better when researchers use the Satisfaction

126 with Life Scale and the Harmony in life Scale to operationalize these constructs (Kjell,

127 Daukantaite, Hefferon \& Sikström, 2016). That being said, harmony in life is distinctive from life

128 satisfaction, not only due to how it is conceptualized or psychometric differences between

129 measures, but also because the meaning of the words people use to describe how they pursue

130 harmony is semantically different from the words people use to describe how they pursue life

131 satisfaction (Kjell et al., 2016). For instance, people use more frequently words such as peace,

132 balance, unity, agreement, calm, mediation, cooperation, tolerant, nature, forgiveness, etcetera,

133 when describing how they pursue harmony in life vs. when describing how they pursue life

134 satisfaction (Kjell et al., 2016). Conversely, people use more frequently words such as job, money,

135 achievement, education, success, wealth, house, gratification, etcetera, when describing how they

136 pursue life satisfaction vs. when describing how they pursue harmony in life (Kjell et al., 2016).

137 Therefore, we go beyond suggesting harmony as a complement to the cognitive component of 
138 subjective well-being and propose that, from a biopsychosocial perspective, harmony in life should

139 be seen as the social component of a general subjective well-being factor.

140 By adding judgements of one's social interactions (harmony in life) to judgements of one's

141 emotional reactions (bio) and judgments of one's life satisfaction (psycho), we used Classical Test

142 Theory (CTT) to investigate different factorial models of our theorized biopsychosocial general

143 subjective well-being factor and its specific sub-factors. Next, we briefly review the current

144 literature that have addressed each component using CTT. Here we only review the most common

145 measure for each of these components (for a compilation of measures see, for example, Lopez \&

146 Snyder, 2004).

147 Three Components, Three Measures

148 The Positive Affect Negative Affect Schedule (Watson et al., 1988) has been used in several 149 studies to assess the affective or biological component of subjective well-being. This instrument 150 consist of 20 items, 10 adjectives that measure positive affect (i.e., "Interested", "Enthusiastic", 151 "Proud", “Alert”, “Inspired”, “Determined”, “Attentive”, “Active”, “Excited”, and "Strong”) and 15210 adjectives that measure negative affect ("Distressed”, "Upset”, “Guilty”, “Afraid”, "Hostile”, 153 "Irritable", “Ashamed", "Nervous", "Jittery", and "Scared”) with a 5-point Likert scale (1 = not at 154 all, 5 = very much). The best representation of positive and negative affect's latent structure is the 155 orthogonal rotation of the factors, perhaps due to the opposing pleasant-unpleasant relationship in 156 the factor loadings (Watson et al., 1988). The scales have shown high internal consistency in 157 different studies - Cronbach's alphas raging between .83 to .90 for positive affect and between 158.85 to .93 for negative affect (see Watson \& Clark, 1994; Leue \& Lange, 2011). Nevertheless, 159 researchers have reported a two-factor model with positive affect and negative affect as both 160 uncorrelated factors and correlated factors (e.g., Crawford \& Henry, 2004; Crocker, 1997; 
161 Kercher, 1992; Krohne, Egloff, Kohlmann, \& Tausch, 1996; MacKinnon, Jorm, Christensen, 162 Korten, Jacomb, \& Rodgers, 1999; Terraciano, McCrae, \& Costa, 2003; Gaudreau, Sanchez, \& 163 Blondin, 2006; Killgore, 2000; Mehrabian, 1997; Ortuño Sierra, Santarén Rosell, perez-albeniz, 164 \& Fonseca-Pedrero, 2015; Ortuño-Sierra, Bañuelos, Pérez de Albéniz, Molina, Fonseca-Pedrero, 165 2019; Sanmartín, Inglés, Vicent, Gonzálvez, Díaz-Herrero et al., 2018). Moreover, using structural 166 equation modeling, the best-fitting models are achieved by specifying correlations between error 167 in items closely related to each other in meaning: Distressed-Upset, Guilty-Ashamed, ScaredAfraid, Nervous-Jittery, Hostile-Irritable, Interested-Alert-Attentive, Excited-EnthusiasticInspired, Proud-Determined, and Strong-Active (e.g., Crawford \& Henry, 2004). Hence, these covariances partially suggest the possibility of item reduction without serious repercussions on the internal consistency reliability of the positive and negative affect scales (Thompson, 2007, 2017). component of subjective well-being (Diener et al., 1985; Pavot \& Diener, 1993; Pavot \& Diener, 2008; Glaesmer, Grande, Braehler, \& Roth, 2011; Moksnes, Løhre, Byrne, \& Haugan, 2014; Ortuño-Sierra, Aritio, Chocarro de Luis, Navaridas Nalda, Fonseca-Pedrero, 2019). The scale consists of five items (i.e., "In most ways my life is close to my ideal", "The conditions of my life are excellent", "I am satisfied with my life", "So far I have gotten the important things I want in life", and "If I could live my life over, I would change almost nothing") with a 7-point Likert response scale ( 1 = "strongly disagree" to 7 = "strongly agree"). The Satisfaction with Life Scale has shown Cronbach's alphas ranging from .79 to .89 (e.g., Pavot \& Diener, 1993; Adler \& Fagley, 2005; Steger, Frazier, Oishi, \& Kaler, 2006; for a meta-analysis see Vassar, 2008). Moreover, in the original article (Diener et al., 1985), a principal-axis factor analysis on the 
184 for $66 \%$ of the variance in the items. Although the single factor solution has been replicated in

185 several studies, the fifth item (i.e., "If I could live my life over, I would change almost nothing")

186 often shows lower factor loadings and lower item-total correlations than the first four items (e.g.,

187 Senécal, Nouwen, \& White, 2000). Probably because this specific item clearly implies an

188 evaluation over one's whole past life, while the other items of the scale imply a focus on the present

189 (e.g., "The conditions of my life are excellent") or a temporal summation (e.g., "In most ways my

190 life is close to my ideal”) (Pavot \& Diener, 2008).

191 The Harmony in Life Scale (Kjell, Daukantaite, Hefferon \& Sikström, 2016) comprises 5

192 items (i.e., "My lifestyle allows me to be in harmony", "Most aspects of my life are in balance",

193 "I am in harmony", "I accept the various conditions of my life", and "I fit well with my 194 surroundings") with a 7-point Likert response scale $(1=$ "strongly disagree" to $7=$ "strongly 195 agree") and similar istructtions as the Statisfaction with Life Scale. The factor loadings range from 196.73 to .90 (e.g., Kjell et al., 2016; Singh, Mitra \& Khanna, 2016) and Cronbach's alphas from .83 197 to .95 in different studies (e.g., Kjell et al., 2016; Garcia, Nima, \& Kjell, 2014; Kjell, Kjell, Garcia, 198 \& Sikström, 2019; Singh et al., 2016). CTT studies show that despite a strong correlation between 199 life satisfaction and harmony in life, the two-factor models, rather than single factor models, are 200 considerable better (Kjell et al., 2016).

201 The present study

202 Our aim was to investigate different factor models of our theorized biopsychosocial model of 203 subjective well-being, and its general factor and specific sub-factors: positive and negative affect 204 (bio), life satisfaction (psycho), and harmony in life (social). We suggest that seeing subjective 205 well-being from a biopsychosocial perspective covers all the parts that compose a human being 206 (i.e., body, mind, and psyche), it also corresponds to a ternary model of human awareness: the self, 
207 others, and something greater than the self, such as, nature, God or the universe (Cloninger, 2014),

208 and to the concept of health as physical, mental, and social well-being (WHO, 1946). To the best

209 of our knowledge, this is the first study to examine a general subjective well-being factor using

210 higher order factor analysis and Bifactor analysis.

\section{Method}

\section{Ethics statement}

213 Ethics approval was not required at the time the research was conducted as per national regulations.

214 The consent of the participants was obtained by virtue of survey completion after they were

215 provided with all relevant information about the research (e.g., anonymity).

\section{Participants and Data Collection Procedure}

217 The participants $(N=600$ in the initial sample, with an age mean of $39.41 s d=12.43$; in which

$21874.60 \%$ were employed for wages and 79.50\% had a Bachelor's degree as their highest achieved

219 educational level) were recruited through Amazon's Mechanical Turk ${ }^{3}$

220 (http://www.mturk.com/mturk/welcome). All participants originated from the USA and spoke

221 English as their first language. Participants were informed that the survey was voluntary,

222 anonymous, that they could terminate the survey at any time and that those who accepted would

223 receive $\$ 0.50$ as compensation for their participation. We added two control questions to the

224 survey, to control for automatic responses (e.g., "This is a control question, please answer "neither

225 agree nor disagree"). The final sample, after taking away those who responded erroneously to one

226 or both of the control questions ( $n=73 ; 12.17 \%$ of all respondents) consisted of 527 participants

227 (200 males and 327 females).

228

\section{Measures}

3 Amazon's Mechanical Turk allows data collectors to recruit participants (i.e., workers) online for completing different tasks for money (for a review on the validity of this method for data collection see among others: Rand, 2011; Buhrmeister, Kwang \& Gosling, 2011). 
229

230

231

232

233

234

235

236

237

238

239

240

241

242

243

244

245

246

247

248

249

250

251

Positive Affect and Negative Affect Schedule (PANAS; Watson et al., 1988) The PANAS instructs

participants to rate to what extent they generally have experienced 10 positive, PA (e.g., "Proud"), and 10 negative, NA (e.g. "Afraid"), feelings and moods during the last week, using a 5- point Likert scale $(1=$ very slightly or not at all, 5 = extremely).

The Satisfaction with Life Scale (SWLS) (Diener et al., 1985) assesses the cognitive component of subjective well-being (i.e., life satisfaction) and consists of five items (e.g., "'In most of my ways my life is close to my ideal") that require a response on a 7-point Likert scale $(1=$ strongly disagree, 7 = strongly agree $)$.

Harmony in Life Scale (HILS) (Kjell et al., 2016) assess a person's global sense of harmony in life and consists of 5 statements (e.g., "My lifestyle allows me to be in harmony") for which respondents are asked to indicate degree of agreement on a seven-point Likert scale $(1=$ strongly disagree, 7 = strongly agree)

\section{Statistical Treatment}

The Expectation-Maximization Algorithm (EM-Algorithm) was used to deal with missing values (less than $0.8 \%$ participants in all variables/items). Little's Chi-Square test for Missing Completely at Random was, $\chi^{2}=590.64(d f=637, p=.91)$. This means that the missing data was missing at random and not systematically; thus, the EM-Algorithm was appropriate for replacing the missing data (Tabachnick \& Fidell, 2007). Based on the EM-Algorithm, 527 participants' responses (males $=200$, females $=327$ ) were found to be valid. All items had skewness between -.01 to 2.35 and kurtosis between -.15 to -2.77 except the items "guilty", "hostile" and "ashamed" with kurtosis = 4.01, 4.26 and 5.26 respectively. The values of skewness and kurtosis regarding these items indicated that we have violated the assumption of normality, so we used Satorra Bentler $\chi^{2}$ in our analysis for model goodness of fit versus the null (independence) model (Tabachnick \& Fidell, 
252 2007). This test is a correction to the chi-squared test and makes standard errors, $p$-values, and

253 confidence intervals robust to nonnormality. The items were averaged to compute SWLS, HILS,

254 NA and PA and then added to compute a subjective well-being total score (SWBS). When we

255 computed the scores and Cronbach's alphas of SWBS we reversed the scores of the NA items. In

256 other words, the raw score of these items are subtracted rather than added in the computations of

257 SWBS because the items are negatively related to the SWBS construct. Items of the four subscales

258 (SWLS, HILS, NA and PA) had different ranges, so we also standardized them before we

259 computed the SWBS average. This was done to make sure that all items contribute equally to

260 SWBS and to make it easier to interpret the result. The scales (SWBS, SWLS, HILS, NA and PA)

261 had skewness between -.19 to 1.65 and kurtosis between .06 to 2.06. See the Supplementary

262 Material for the details (Table S1).

263 Statistical Procedure

We used the following software to analyse the data: STATA version 14, SPSS version 24 and Microsoft Excel. As a first analysis, we tested and described the map of correlations among all items (30 items) in our study, and the correlations among SWBS (simple average of standardized scores of all items including reserved scores of NA items) and its four specific subscales (SWLS, HILS, NA and PA) using Pearson's correlation coefficient (Table S2). In the second analysis, we investigated convergent and discriminant validity by conducting a Person correlation analysis between SWLS, PA, NA, HILS.

As a third analysis, our main statistical procedures were: (1) to run exploratory factor analyses (EFA) using principal component analysis (PCA) to describe and cover the underlying structure regarding proposed models of the scales (SWBS, SWLS, HILS, NA and PA) as five separate latent traits, (2) to run confirmatory factor analyses (CFA) using structural equation 
275

276

277

278

279

280

281

282

283

284

285

286

287

288

289

290

291

292

293

294

295

296

297

modelling (SEM) with robust maximum likelihood (ML) (Satorra \& Bentler, 2001) estimation to test our theoretical model and to determine whether measures of each construct are consistent with earlier understandings of the nature of underlying factorial structure (latent trait) of these scales (SWBS, SWLS, HILS, NA and PA). We applied five different EFA and CFA models: (a) to investigate if the correlation among items in each specific subscale were explained by only a single latent trait (four separate unidimensional factor structures), (b) to test that the correlations among all 30 items were dependent on only a single general latent trait (unidimensional factor structure of SWBS), (c) to test the proposed multidimensional correlated model of the subscales (SWLS, HILS, NA and PA) without a single general latent trait (SWBS), (d) to test a higher order multidimensional factor model (second order model) using SWBS as single general latent factor and a second order factor and using the subscales (SWLS, HILS, NA and PA) as specific first order factors and domains/traits, (e) to test a bifactor model (that can be considered as a nested factors or hierarchical factor model) to investigate the proposed multidimensional factor structure of SWBS and its subscales, in which every item is affected by both SWBS as a single general latent trait and by and only by its respective subscale (SWLS, HILS, NA and PA) as orthogonal secondary dimensions.

As a fourth set of analyses, we tested the scales reliability using both Cronbach's alpha reliability coefficient and Omega reliability coefficients. We used Cronbach's alpha coefficient to evaluate the internal reliability of each subscale and the overall scale of SWBS. All scales in our study had high reliability, with Cronbach's alpha ranging from .92 for PA to .96 for SWBS. See the Supplementary Material for the details (Table S3). This high internal reliability could, however, be explained due to the fact that Cronbach's alpha coefficient is influenced by different sources (i.e., general, group, and specific factors). Moreover, the high internal reliability, as 
measured by Cronbach's alpha, might be just a reflection of the reliability of all these sources without partitioning. Importantly, Cronbach's alpha is based on observed variances and covariances and assumes that all items have equal loadings on the latent factors, hence, it depends on the average item intercorrelation and the number of items in the scale (i.e., as the number of items and the intercorrelation values increase, so does Cronbach's alpha) (Rodriguez et al., 2016). As the matter of fact, Cronbach's alpha may indicate high internal reliability even when the data reflects highly multiple latent structures, or it can also underestimate internal reliability when the data has a unidimensional latent structure. Indeed, when the data has a multidimensional structure,

Cronbach's alpha is affected by all sources of common and specific item variance, and it can overor under-estimate the reliability of the scale(s). Moreover, in this case, it is not entirely straightforward what the correct interpretation of "true score" variation is because the "true score" itself also is a weighted composite of multiple latent dimensions (Reise et al., 2018). With these limitations of Cronbach's alpha in mind, we also computed Omega reliability coefficients, which have high generalizability and could also help us to avoid the limitations of the Cronbach's alpha coefficient. Omega coefficients are based on factor loadings, do not assume equal loadings, and can separate out the reliable item's variance to either latent general factors or latent subscales factors. In other words, Omega calculations take into consideration both general and group sources of common variance as "true score" variance and estimates the reliability of a multidimensional scale (Reise et al., 2018). In our study we computed five Omega coefficients. (1) Omega total

317 (?Total), which is a reliability estimate that provides information of the amount of the common variance of items' variance in a given model that belongs to a reliable variance for the general latent factor and also for specific subscale(s). (2) Omega hierarchical (? $H$ ), which is a reliability estimate that provides information about the amount variance of all items in a given model that 
321 belongs only to a reliable variance for the general latent factor. (3) Omega hierarchical subscale 322 (? $H S$ ), which is a reliability estimate that provides information of the amount of the subscale 323 reliable variance after controlling for reliable variance due to the general latent factor. (4) Omega 324 subscale (?S), which is a reliability estimate that provides information of the amount of the 325 subscale reliable variance due to both the general latent factor and the specific corresponding 326 subscale. Finally, (5) Omega general for subscale, which is a reliability estimate that provides 327 information of the subscale reliable variance in a given model accounted only by the reliable 328 variance of the general latent factor.

As a fifth analysis, we computed explained common variance (ECV). The ECV is a

330

331

332

337

338

341

\section{Results and Discussion}

\section{The Map of Correlations among All Items}

The map of correlations among items in our study showed that most of the correlations were high and significant, ranging from $-.12, p<.01$ to $.91, p<.01$. The largest correlation, both within and between subscales, was between the item "Most aspects of my life are in balance" and the item "I am in harmony" $(r=.91, p<.01)$ and the lowest was between the item "Inspired" and the item "Guilty" ( $r=-.04, n s)$. Some items, such as the item "Alert", had however only low correlations to items within and outside its specific subscale. Thus, we expected that this specific item might 
344 not be a good marker of the positive affect subscale or the general latent factor of SWB. Indeed,

345 item covariances between items of the different subscales are pure reflections of general factor

346 saturation, whereas covariances between items within subscales reflect a mixture of general factor

347 saturation and group factor saturation (Zinbarg et el., 2007). That being said, this map of

348 correlations showed also that many items within each specific subscale are highly correlated with

349 each other and also across the other subscales. In other words, reflecting that a multidimensional

350 construct, in which each item is influenced by multiple latent factors, might fit our data better

351 rather than a unidimensional latent construct, in which each item is influenced by a single latent

352 factor.

353 Convergent and Discriminant Validity

354 In order to test convergent and discriminant validity we investigated the Pearson correlations

355 between the different scales, which ranged between from $-.34, p<.01$ to $.83, p<.01$. The SWLS

$356(r=.52, p<0.01)$ and HILS $(r=.55, p<0.01)$ were positively and significantly correlated with

357 the PA. Conversely, the SWLS $(r=-.51, p<0.01)$ and HILS $(r=-.60, p<0.01)$ were negatively

358 and significantly correlated with NA. Moreover, PA and NA were negatively and significantly

359 correlated with each other $(r=-.34, p<0.001)$. The largest correlation was between SWLS and

360 HILS $(r=.83, p<.01)$. Hence, there is sufficient convergent and discriminant validity between

361 the model's four different constructs. See the Supplementary Material for the details (Table S3).

362 Exploratory Factor Analyses (EFA) and Confirmatory Factor Analyses (CFA)

363 As a first step we used a series of EFA and CFA that tested whether the correlation among items

364 in each specific subscale were explained by only its single latent trait. We applied four separate

365 unidimensional factor structure models for SWLS, HILS, NA and PA. First, we conducted four

366 separate EFA using PCA to examine the latent structure for each subscale. An eigenvalue greater 
367 than one (eigenvalues $>1$ ) was chosen as suitable criterion to determine that a reasonably large 368 proportion of the total variance corresponded to at least one factor. The results showed that each

369 subscale had only one eigenvalue that was greater than one, except for PA which had two 370 eigenvalues that were greater than one (4.08 for SWLS, 4.21for HILS, 6.56 for NA and both 5.88 371 and 1.18 for PA). Because of the large difference between the first (5.88) and the second (1.18) 372 eigenvalue regarding PA, we interpreted that the largest eigenvalue accounted for one extracted 373 factor with a reasonably large proportion of the total variance. We also applied Horn's Parallel Analysis for the selection of the correct number of components in an exploratory factor analysis 375 (Horn 1965). Using this criterion, the number of factors to retain corresponds to the highest eigenvalues generated from the researcher's dataset in comparison to the randomly generated eigenvalues. Our result showed that all eigenvalues larger than one generated from our dataset were larger than the corresponding random percentile eigenvalues, except for one of the two PA eigenvalues larger than one (i.e., 1.18). All items were highly and positively loaded. Loadings of 380 items ranged between .81 to .94 for SWLS, between .84 to .95 for HILS, between .76 to .88 for NA and between .72 to .85 for PA. The only exception was the item "Alert" in the PA subscale, with a relativity lower loading (.60). factor structures of each subscale. Regarding SWLS, the result showed that the chi-square value was significant $\left(\chi^{2}=45.30, d f=5, \mathrm{p}<.001\right)$, Satorra Bentler $\chi^{2}$ was significant $\left(\mathrm{S}-\mathrm{B} \chi^{2}=26.38, d f\right.$ $=5, \mathrm{p}<.001)$, the comparative fit index $(\mathrm{CFI})$ was .99, Tucker-Lewis index (TLI) was .98 and the root mean square error of approximation (RMSEA) was .09. However, the chi-square statistic is heavily influenced by sample size (Kline, 2010), with larger samples leading to larger value and therefore, a larger likelihood of being significant. Thus, all indices indicated that the model fit was 
390

391

392

393

394

395

396

398

400

401

402

403

404

405

406

407

408

409

410

411

412

acceptable (cf. Bollen, 1989; Browne \& Cudeck, 1993). All the standardized regression loadings between SWLS and its items were significant at $p<.001$ (ranging from .87 to .94) with the exception of the item "If I could live my life over, I would change almost nothing", which had a loading of .74. See the Supplementary Material for the details (Figure S1). For instance, this specific item often shows lower factor loadings and item-total correlations than the first four items (e.g., Senécal, Nouwen, \& White, 2000). Probably due to the fact that this item clearly implies an evaluation over one's whole past life, while the other items of the SWLS imply a focus on the present or a temporal summation (Pavot \& Diener, 2008).

Regarding HILS, the results showed that the chi-square value was significant $\left(\chi^{2}=87.65\right.$, $d f=5, \mathrm{p}<.001)$, Satorra Bentler $\chi^{2}$ was significant $\left(\mathrm{S}-\mathrm{B} \chi^{2}=47.41, d f=5, \mathrm{p}<.001\right)$, CFI was .98 , Tucker-Lewis index (TLI) was .96 and RMSEA was .13. Thus, while the comparative fit index and Tucker-Lewis index generally indicated good model fit but the root mean square error of approximation indicates that the model was not a good-fitting model. All the standardized regression loadings between this scale and its items were significant at $p<.001$ (ranging from .86 to .96) with the exception of the item "I accept the various conditions of my life.", which had loading .76. See the Supplementary Material for the details (Figure S2).

Regarding PA, the results showed that the chi-square value was significant $\left(\chi^{2}=508.33, d f\right.$ $=35, \mathrm{p}<.001)$, Satorra Bentler $\chi^{2}$ was significant $\left(S-B \chi^{2}=350.72, d f=35, \mathrm{p}<.001\right)$, CFI was .88 , TLI was .84 and RMSEA was .13. Hence, indicating that the model fit was not acceptable. All the standardized regression loadings between this scale and its items were significant at $p<.001$ (ranging from .70 to .85) with the exception of the item "Attentive" and "Alert", that had loadings of .64 and .51, respectively. See the Supplementary Material for the details (Figure S3). Regarding NA, the results showed that the chi-square value was significant $\left(\chi^{2}=520.12, d f=35\right.$, 
$413 \mathrm{p}<.001)$, Satorra Bentler $\chi^{2}$ was significant $\left(S-B \chi^{2}=233.83, d f=35, \mathrm{p}<.001\right)$, CFI was .90, TLI

414 was .89 and RMSEA was .10. Thus, these fit indexes indicated a poor model fit. All the

415 standardized regression loadings between this scale and its items were significant at $p<.001$

416 (ranging from .71 to .88). See the Supplementary Material for the details (Figure S4).

417 In general, high values of RMSEA indicated that the models were not good enough fitting

418 models $^{4}$. Moreover, these high values suggest that there are large residuals in these models, that

419 might be caused by measurement error and/or a latent multidimensional structure. If these residuals

420 are caused by a latent multidimensional structure, we expected that it would reflect both general

421 and specific latent factors as theorized by our biopsychosocial model of SWB.

422

We applied EFA and CFA to test if the correlations among all 30 items are explained by

only one single latent trait (unidimensional model for SWBS). We conducted EFA using PCA to

test this model. The results revealed four eigenvalues that were greater than one (eigenvalues $>1$ ).

Eigenvalues were 13.63, 4.14, 2.57 and 1.14. Because the large different between the first and the

other eigenvalues, we interpreted that one extracted factor accounted for a reasonably large

proportion of the total variance, that is, the largest eigenvalue (13.63). Horn's Parallel Analysis

was also applied and showed that the first three eigenvalues (13.63, 4.14 and 2.57) generated from

our dataset were larger than the corresponding random percentile eigenvalues. All items were

positively loaded except for the items of NA, which were negatively loaded. Loadings of items ranged between .52 to .85 (the only exception was the item "Alert", which had weak load .37). We

conducted also CFA using SEM to test whether the correlations among all 30 items were explained

these items yielded negative factor loadings with SWBS. The results showed that the chi-square

\footnotetext{
${ }^{4}$ RMSEA, however, is known to be inflated with low $d f$ models (Kenny, Kaniskan, \& McCoach, 2015). Therefore, we have used multiple indices to provide different information about the model fit. Used together, these indices provide a more conservative and reliable evaluation of the model fit (Maruyama, 1997).
} 
435 value was: $\chi^{2}=6613.79, d f=405, \mathrm{p}<.001$, the Satorra Bentler $\chi^{2}$ was: $S-B \chi^{2}=4991.18, d f=405$,

$436 \mathrm{p}<.001$, and that the $\mathrm{CFI}=.58, \mathrm{TLI}=.55$ and $\mathrm{RMSEA}=.15$. All the standardized regression weights

437 were significant at $p<.001$ (ranging from .40 to .91) with the exception of the item "Alert", which

438 had loading .29. See the Supplementary Material for the details (Figures S5 and S6). In general,

439 low values of CFI and TLI, and RMSEA indicated that the model was not a good enough-fitting

440 model. This high value of RMSEA suggested high large residuals in these models, that could be

441 caused by a latent multidimensional structure that contains both general and specific latent factors.

442 Thus, we made some modifications to get a better fitting regarding this model.

We applied CFA using SEM analysis to test the proposed multidimensional correlated

model in which the items were loaded to only one of the multiple dimensions (SWLS, HILS, NA

and PA). The result showed that the chi-square value was significant $\left(\chi^{2}=1875.24, d f=399, \mathrm{p}<\right.$ $.001)$, Satorra Bentler $\chi^{2}$ was also significant $\left(S-B \chi^{2}=1413.64, d f=399, \mathrm{p}<.001\right)$, and a CFI $=$ $.91, \mathrm{TLI}=.90$ and RMSEA $=.07$. Hence, indicating that the model fit was acceptable. All the standardized regression weights were significant at $p<.001$ (ranging from .74 to .94 for SWLS, .76 to .96 for HILS, .51 to .85 for PA and .71 to .89 for NA) and all the correlations among subscales were also significant at $p<.001$ (ranging from -.38 between PA and NA to .88 between SWLS and HILS). This model was, however, unable to give us adequate information about the overall score (i.e., SWBS) because it contained only four correlated specific subscales. In other words, this model was not able to measure and capture a single common latent factor of subjective well-being. See the Supplementary Material for the details (Figure S7). model), that represents the proposed multidimensional factor structure of SWBS and its specific subscales. In this model, the subscales are dependent on only SWBS as a single general latent trait, 
458

459

460

461

462

463

464

465

466

467

468

469

470

471

472

473

474

475

476

477

478

479

480

and items are dependent on only one of the specific subscales. The results showed that the chisquare value was significant $\left(\chi^{2}=1881.49, d f=401, \mathrm{p}<.001\right)$, the Satorra Bentler $\chi^{2}$ was also significant $\left(S-B \chi^{2}=1419.90, d f=401, p<.001\right)$, and a CFI $=.91$, TLI $=.90$ and $\mathrm{RMSEA}=.07$. Thus, indicating that the model fit was acceptable. All the standardized regression weights were significant at $p<.001$, between SWBS and its subscales (ranging from .60 to .96), and between each subscale and their items (ranging from .74 to .94 for SWLS, .76 to .96 for HILS, .51 to .85 for PA and .70 to .89 for NA). In this model, the correlations (double headed arrows) among subscales (first order latent factors) in Figure S8 are explained by a higher order factor (SWBS) as a single general latent factor that could account for their effect. Moreover, SWBS could directly influence its specific subscales but it could only indirectly influence each item. In sum, this model did not clearly describe the effect of a general latent subjective well-being factor on each item because these specific subscales (first order traits) mediated this effect, so there was no direct relationship (pathway) between SWBS and each item. In this model, we reversed the scores of the NA items, because these items yielded negative factor loadings with SWBS. See the Supplementary Material for the details (Figures S8 and S9).

We applied CFA using SEM analysis to investigate the proposed multidimensional factor structure of SWBS and its subscales as a bifactor model. In this model, all items were specified to load on SWBS as a single general latent trait and on one and only one corresponding specific subscale (i.e., SWLS, HILS, NA and PA) as specific factor. Moreover, in this model, all included factors (i.e., SWBS, SWLS, HILS, NA and PA) were orthogonal and uncorrelated with one another. The fit indices were acceptable $\left(\chi^{2}=1660.78, d f=375, p<.001 ; S-B \chi^{2}=1265.80, d f\right.$ $=375, p<.001 ; \mathrm{CFI}=.92, \mathrm{TLI}=.91$ and $\mathrm{RMSEA}=.067)$, thus, indicating that this model was the best model regarding fit indexes compared with the all other models in this study, so we considered 
481 this model in our further analysis. All the standardized regression weights were significant at $p<$ 482.001 , except the loadings from HILS to its specific items, which were significant but at different 483 levels (HILS1 at $p<.001$, HILS2 at $p<.01$, HILS3 at $p<.01$, HILS4 at $p<.01$ and HILS at $p<$ 484 .05). The standardized regression weights on SWBS for each item ranged from .62 to .85 for items 485 of SWLS, .82 to .96 for items of HILS .39 to .62 for items of NA, and .25 to .57 for items of PA. 486 The standardized regression weights on specific subscales for their respective items ranged from 487.37 to .47 for SWLS, -.46 to .18 for HILS, .45 to .67 for PA and - .54 to -.71 for NA. In this model, 488 we reversed the scores of the NA items because these items could yield negative factor loadings on SWBS (Figure 1; see also Figure S10 for the original model with non-reversed NA items in the Supplementary Material). In general, the results from the bifactor model indicated that: (1) the model fit indices were acceptable and the best ones compared with the other tested models in this study, (2) the loadings of HILS' items on the general latent factor (SWBS) were very high and the highest and at the same time the loadings of these items on the specific latent factor (HILS) were very low and the lowest, thus, indicating that the HILS' items contributed highly to the general factor (SWBS) but no to HILS itself, (3) the loadings of items of SWLS on the general latent factor (SWBS) were also high and still high but moderate for the specific latent factor (SWLS), thus, confirming that the SWLS' items contributed to a higher degree to the general factor (SWBS) compared to the items' contribution to SWLS, and (4) the loadings of items of PA and NA on the general latent factor (SWBS) were lower compared with the loadings of these items on their corresponding specific latent factor (PA respectively NA), thus, indicating that the PANAS' items reflected a mixture of general latent structure saturation and specific latent structure saturation, but 503 (SWBS). 

right. Next, we go through all details regarding the bifactor model.

\section{Factors' Eigenvalues for the Bifactor Model}

514 The results showed that general factor (SWBS) had a large eigenvalue 11.47, that two of the 515 subscales had eigenvalue greater than one (3.58 for PA and 3.73 for NA), and that HILS and SWLS 516 had eigenvalues that were less than one (.91 for SWLS and .29 for HILS). These eigenvalues 517 together with the results presented above indicated that most of the variance in total scores in this 518 given bifactor model could be attributed to the SWBS as a general latent factor and to the PA and

519 NA as two specific latent factors. Moreover, the eigenvalue for SWLS indicated that SWLS might

520 be interpreted as a specific latent factor, while HILS was clearly not a specific latent factor.

\section{Reliability Coefficients for the Bifactor Model}

522 The results indicted that Omega total was .79 (Cronbach's alpha was .96 for SWBS, ranging from .92 to .95 for the subscales). Thus, both the general latent factor (SWBS) and the specific latent subscales (SWLS, PA, NA, and HILS) could explain 79\% of the total variance of all 30 items in

526 (uniqueness) and therefore not explained by the bifactor model. Omega hierarchical was .64, thus, 
$52764 \%$ of the variance in total scores could be attributed to SWBS as a single general latent factor.

528 Importantly, a value above .50 regarding Omega hierarchical indicates a broad general latent trait

529 (Reise et al., 2013). Moreover, the value of Omega hierarchical indicated also that 81\% (.64/.79

$530=.81$ ) of the common variance in total scores belonged to a single general latent factor (i.e.,

531 SWBS). About $15 \%(.79-.64=.15)$ of the variance in total scores was estimated to be due to all

532 specific latent traits (SWLS, HILS, NA and PA). In other words, for the bifactor model, 19\% of

533 reliable common variance (i.e., the reliable variance for both the general factor and subscales) in

534 total scores could be attributed to the specific subscales (i.e., SWLS, HILS, NA and PA).

535 On the subscale level, Omega hierarchical subscales were .22 for SWLS, .00 for HILS ${ }^{5}$,

536.48 for PA, and .49 for NA, while Omega subscales were .94 for SWLS, .98 for HILS, .72 for PA,

537 and .81 for NA. This indicated that, in the bifactor model, when the reliable variance of the single

538 general latent factor (SWBS) was removed from the subscales, the reliability of the specific

539 subscales was largely reduced due to the large effect of the general latent factor (SWBS). This

540 means, for example, that the extremely high value of Omega subscale for HILS (.98) was caused

541 by the extremely high positive loadings between the HILS' items and the general factor (i.e.,

542 SWBS; .92 for HILS1, .94 for HILS2, .95 for HILS3, .82 for HILS4, and .88 for HILS5). Thus,

543 the .00 value of Omega hierarchical subscale for HILS was caused by the small and negative

544 loadings between the HILS' items onto the HILS subscale (.18 for HILS1, .13 for HILS2, .13 for

545 HILS3, -.46 for HILS4, and .18 for HILS5) and probably also influenced by both positive and

546 negative loadings, thus, cancelling each other out (Rodriguez et al., 2016). Based on these results,

547 we argue that the high loadings between the HILS' items and HILS as a single latent factor (See

\footnotetext{
5 The negative loadings regarding HILS4 "I accept the various conditions of my life" and HILS5 "I fit in well with my surroundings" on their corresponding subscale made us use absolute values of factor loadings. Then we calculate the sum of these loadings to calculate omega indices. The result didn't differ, except with small changes regarding Omega hierarchical subscale for HILS (changed from .00 to .05), Omega hierarchical (changed from .64. to .63) and Omega general for subscale (changed from .98 to .93). See Table S4.
} 
548 Figure S2) belong to the latent trait of SWBS rather than the latent trait of HILS. In other words,

549 the high loadings between the HILS' items and the HILS single factor reflect merely the effects of

550 the shared variance caused by the repeated item content, rather than each item's relation with HILS

551 as a single factor. Thus, the HILS' items do not reflect any shared variance or maybe just minimal

552 variance of HILS as a subscale. For instance, some of the HILS' items contained words that do not

553 directly address balance, adaptation or harmony, which are keywords people use to refer to the

554 sense of harmony (Kjell et al., 2016) or themes that could be easily misimterpreted. Indeed,

555 harmony is a construct that indicates how people think about their life in relation to the world

556 around them - a process that involves acceptance and adaptation in order to bring balance to one's

557 life (Garcia, Nima, Granjard \& Cloninger, under editorial evaluation). For example, in HILS4: "I

558 accept the various conditions of my life" the keyword is "accept" and in HILS5 "I fit in well with

559 my surroundings" the keyword is "fit". In HILS5, the word "surrounding" might be experienced

560 as unclear or vague, is the participant supposed to think about only physical near places or even

561 family, work, friends, nature? Also, in this line, regarding HILS4, is it necessary for harmony to

562 only "accept" the conditions of one's life even if they are bad conditions? Or is the process of

563 harmony comprised of both acceptance and then adaptation in order to find balance or

564 homeostasis? We find it plausible to suggest that the lack of the process of adaptation and

565 homeostasis as a part of a harmonious life in HILS4 is what generated the negative loadings for

566 this item. Certainly, we may accept bad situations, bad surroundings, and bad conditions that are

567 outside of our possibility to change or avoid, but if we are flexible, resourceful, kind and self-

568 aware, we would be able to do many things to adapt by improving ourselves, others or moving

569 away from the bad situation (Cloninger, 2004). So, we conclude that such items should be removed

570 or modified accordingly and then tested again to see if they support or not our theoretical model. 
572 respectively. This indicated that the SWLS items tended to load higher on the general latent factor

573 (SWBS) than on their corresponding subscale (SWLS). In other words, only small reliable variance

574 on the subscale (SWLS) level remained when the general latent factor was controlled for. This

575 subscale reliability is mostly attributable to individual differences on the general latent trait, which

576 had an Omega general for subscale $.72(.94-.22=.72)$. The values of Omega hierarchical 577 subscales for PA (.48) and for NA (.49) and Omega subscale for PA (.72) and for NA (.81) showed

578 that the PA and NA items tended to load higher on their corresponding subscales than on the 579 general latent factor (SWBS). PA and NA's reliability of a subscale scores were still high after 580 removing the reliable variance of the general factor. Additionally, both values of Omega general 581 for subscale (.25 for PA and NA.32) and factor loadings on their corresponding subscale (ranging 582 for PA from .25 to .57 and for NA from .39 to .62) showed that items of PA tended to load lower 583 on the general latent factor compared with items of NA. See the Supplementary Material for the 584 details. In this context, there is extensive evidence that PA and NA are best thought as two distinct 585 and dissociable factors and some evidence that they have different heritability, NA showing the 586 strongest genetic influence (for a review see Cloninger \& Garcia, 2015). Thus, probably explaining 587 the differences found here.

588 Explained Common Variance (ECV) for the Bifactor Model

589 The result indicated that $57 \%$ of the common reliable variance (i.e., reliable variance due to single 590 general factor and group factors) was explained primarily by the single general factor (SWBS). In 591 other words, $43 \%$ of common reliable variance in all 30 items in our bifactor model was spread 592 across the subfactors (i.e., SWLS, HILS, PA and NA). In general, high value of ECV indicates 593 that the model has a strong general latent dimension rather than latent subdimensions. Thus, our 
594 results indicated that both the single general factor and the group factors contributed to the 595 common reliable variances in our bifactor model. The high factor loadings on SWLS and HILS 596 might have caused the high ECV values $(.57=57 \%$ of common reliable variance $)$ and the high 597 ? $H(.64=.64 \%$ of variance in total score $)$, whereas the high factor loadings on NA and PA might 598 have caused $43 \%$ of the common reliable variance that was spread across the subscales. Thus, indicating the presence of a multidimensional structure that contains both a single general factor and subfactors. Indeed, tests of ECV calculations using various datasets suggests that data with

$601 \mathrm{ECV}<0.70$ are multidimensional and should therefore be decomposed into multiple scales (ECV $602>0.90$ indicates unidimensionality; Quinn, 2014).

603 Item Explained Common Variance (I-ECV) for the Bifactor Model

604 I-ECV is suggested as a useful index to identify the percentage of expected common variance by 605 the general latent factor at the item level. The result showed that the means of I-ECV were .76 for 606 SWLS, .93 for HILS, .34 for PA, and .40 for NA. The values concerning HILS (.93) and SWLS 607 (.76) showed clear strong effects sizes for the loadings between the HILS and SWLS items and 608 the general factor, whereas the lower values concerning PA (.34) and NA (.40) showed clearly that 609 the majority of the percentage of expected common variance was explained by the loadings 610 between the PA and NA items and their corresponding subfactors rather than the loadings between 611 the PA and NA items and the general factor. I-ECV can also be applied to get a broad sense of the 612 extent to which items in a model can be selected to represent only a unidimensional factor as a 613 good indicator of the general dimension. Items that have values above .80 or .85 are suggested to 614 largely reflect a general dimension as a broad construct (Stucky \& Edelen, 2014). Thus, SWLS 615 and HILS had a tendency for SWBS rather than their respective original concepts, whereas PA 616 and NA had a tendency for their respective original concepts rather than SWBS. However, some 
617 items contributed equally to both the general factor and their respective subfactors (i.e., I-ECV 618 values: .50 for "Distressed", .49 for "Upset", and .48 for "Irritable"). Moreover, the item "Alert" 619 and the item "Attentive" had the largest error variances (uniqueness) .74 and .58 respectively. 620 Thus, $74 \%$ and $58 \%$ of the variance in these items was unique and did not share reliable variance 621 with any other items in our bifactor model. So, these items should be removed or modified (Table 622 1). Indeed, these very same items, "Alert" and "Attentive", provided lesser information when Item 623 Response Theory was applied using a different sample (Nima, Cloninger, Persson, Sikström \& 624 Garcia, 2020). Regarding affect, some theories suggest that besides the dimension of positive and 625 negative, there is a high and low activation dimension (Russell, 1980; Russell \& Feldman Barret, 626 1999). In this model, emotions are categories that are vertically organized as a fuzzy hierarchy and 627 horizontally organized as part of a circumplex (Russell \& Feldman Barret, 1999). In this 628 circumplex, "Alert" and "Attentive" are categorized on the highest point of the high activation 629 dimension and at the lowest point of the positive dimension. It is therefore plausible to suggest 630 that it is this specific feature (i.e., low positive and high activation types of emotions) in these 631 items what causes the problems highlighted using both CTT here and Item Response Theory in 632 other studies (e.g., Nima et al., 2020).

\section{Traditional Average Scores and Factor Scores between Models}

634 We calculated the scores for all scales (SWBS, SWLS, HILS, NA and PA) using the traditional 635 average score approach and the different models' factor scores (i.e., unidimensional model, 636 correlated factors model, second order factor model and bifactor model). See Table 2 and 3 for the 637 details. Additionally, we tested and described the correlations among all the different scores of 638 each scale using Pearson's correlation coefficient. The result showed that all the correlations were 639 very high and significant $(p<.01)$ regarding the scores computed using the traditional average 
640 score, the unidimensional model, the correlated factors model, and the second order factor model.

641 The correlations ranged between .99 and 1.00 for SWLS, from .99, to 1.00 for HILS, from .99 to

6421.00 for PA, from -1.00 to .99 for NA, and from .91 to .99 for SWBS. Then we compared the score

643 distributions for all different models in our study. The bifactor model had a clear tendency to fit

644 normal distribution better than all the other models (Table 2 and 3). See also the Supplementary

645 Material for the details (Figures S11 to S15). In general, these results confirmed that there are no

646 differences within scores for each of the scales between these modes, except for the scores

647 regarding the bifactor model. These results suggest that the loadings of each item within each scale

648 did not vary across the following models: unidimensional model, correlated factors model and

649 second order factor model. However, there were small differences among scores of SWBS

650 regarding the traditional average score approach, the unidimensional model scores, and the second

651 order factor model scores. These small differences might suggest that not all items could measure

652 features of SWBS equally. In other words, the traditional average score approach seems to ignore

653 the possible differences within the items, thus, assuming equal contribution of each item on SWBS.

654 However, the standardized loadings are actually different across the items (e.g., "Alert" had low

655 and the lowest standardized loading .29). The small loadings of items on SWBS caused the factor

656 scores to be undervalued, whereas, the high loadings of items influenced factor scores for SWBS

657 to a higher degree. These small differences could be also caused by the indirect relationship

658 between SWBS and each item in the second order factor model, whereas, the relationship between

659 SWBS and each item were direct in all the other models. In other words, the complicated second 660 order factor model, with indirect relationships between SWBS and the 30 items, was less clear

661 with regard to the item variance explained by SWBS, due to the mediating sub-paths across SWLS,

662 HILS, NA and PA. Moreover, the SWBS score contained more items (30 items) compared with 
663 any of the subscales (e.g. SWLS had only 5 items), so the differences concerning the number of 664 loadings might have a more dramatic effect on the SWBS scores than on the scores of the 665 subscales. Finally, the results regarding the bifactor model were very different. The correlations 666 within each scale' scores from the other models and the bifactor model scores ranged from .46 ( $p$ $667<.01)$ to $.54(p<.01)$ for SWLS, from -.01 $(n s)$ to $.11(p<.05)$ for HILS, from $.80(p<.01)$ to .83 $668(p<.01)$ for PA, from $-.76(p<.01)$ to $.79(p<.01)$ for NA, and from $.89(p<.01)$ to $.99(p<.01)$ 669 for SWBS.

670 In sum, (a) the traditional average score approach consider the items as unweighted items, 671 thus, assuming equal contribution from each item in the construct, whereas factorial models (e.g., 672 the bifactor model or any of the other models used here) allow for the loading of each item to 673 contribute as weighted items, (b) in the traditional average score approach and the unidimensional 674 model, the items are influenced only at the single factor level, whereas, in the bifactor model, the 675 items are influenced and determined by both the single general factor and the subfactor level, (c) 676 the correlated factors model consisted of only four interrelated subfactors, whereas the bifactor 677 model consisted of one general factor and four specific subfactors where no orthogonal 678 correlations were assumed among these factors, and (d) the second order factor model could not 679 clearly describe the effect of general latent factor (SWBS) on each item because the first order 680 scales (SWLS, HILS, NA and PA) mediated this effect, whereas the bifactor model had only a 681 direct pathway from SWBS onto each item, so the association between general latent factor and 682 each item could be freely estimated and was not dependent on any mediating sub-paths.

683 Using the bifactor model, we were able to clearly separate the influence from the broad 684 dimension (SWBS) and each subdimensions (SWLS, HILS, NA and PA) on each item. The 685 bifactor model was successful in covering the general latent dimension, and allowed us to calculate 
686 the scores for specific latent dimensions in a more precise and purified form without the weakness

687 of the other models (e.g., indirect correlations, unweight items effect). In addition, the bifactor 688 model showed large differences in score distributions, while the other models showed almost equal 689 score distributions. So, we suggest that the bifactor model could clearly describe and support the 690 notion of a biopsychosocial model. Nevertheless, as also suggested by our findings, there are some 691 items that need to be modified or removed.

\section{Conclusion}

693

694

695

696

697

698

699

700

701

702

703

704

705

706

707

708

The results indicated that the multidimensional models fit the data better than the unidimensional models. Both general latent factor (SWBS) and specific latent subscales could explain $79 \%$ of the total variance in our bifactor model. This is a clear indication of the presence of a multidimensional structure that contains both a general factor and subfactors. The SWLS items tended to load higher on the general latent factor (SWBS) than on their corresponding subscale (SWLS). In other words, only very little reliable variance on the SWLS subscale remained when the general latent factor was removed, and this reliability of subscale was mostly attributable to individual differences on the general latent trait rather than to individual differences on the specific latent trait. The PA and NA items reflected a mixture of general latent structure saturation and specific latent structure saturation, but they contributed more to their respective specific latent factor than to the general latent factor (SWBS). Moreover, in the bifactor model, 74\% of the variance for Alert" and 58\% of the variance for "Attentive" were error variances (uniqueness) and did not share reliable variance with any other of items within the model. So, we recommend to remove or replace these items following the recommendations found elsewhere using Item Response Theory (e.g., Nima, Cloninger, Persson, Sikström \& Garcia, 2020). The HILS items contributed to a very high degree to the general factor (SWBS), but they did not contribute to HILS itself. For example, the items "I 
709 accept the various conditions of my life" and "I fit in well with my surroundings" had even

710 negative loadings with the HILS subscale within the bifactor model. Moreover, despite the fact

711 that the NA scale tended to contribute more to itself than to the SWBS, some NA items (i.e.,

712 "Distressed", "Upset" and "Irritable" with I-ECV values = .50, .49 and .48, respectively)

713 contributed equally to both the general factor and the NA subfactor. That being said, we suggest

714 that the bifactor model was useful and an appropriate methodological alternative that allowed us

715 to calculate purified scores concerning general and specific latent factors compared with the

716 traditional average score approach and any of the other models (for benefits an limitation of

717 bifactor analysis see Bornovalova, Choate, Fatimah, Petersen \& Wiernik, 2020). The bifactor

718 model could capture the nature of multidimensionality as suggested by our biopsychosocial

719 approach towards subjective well-being, which considers all parts of human health and well-being:

720 physical, psychological, and social.

\section{Limitations, Strengths, and Final Remarks}

722 One of the limitations with factorial models is that they are heavily influenced by the sample characteristics, such as, number of participants (e.g., Nima et al., 2020). However, according to

724 Thompson (2004) if the factors are defined by four or more measured variables with structure coefficients $<.60$, then the sample size if not important. Moreover, if the factors are defined with 10 or more structure coefficients each around .40, then the sample size should be at least 150 . Any sample size over 300 is considered adequate (see for example Comrey \& Lee, 1992, who suggest that 50 cases is very poor, 100 is poor, 200 is fair, 300 is good, 500 is very good, and 1,000 or more is excellent) and 10 observations per variable is suggested as a minimum necessary to avoid computational difficulties. In other words, we suggest that our sample size $(N=527)$ with high

731 loadings in most of the items is adequate and even very good for the analyses conducted. That 
732 being said, despite the fact that we used different factorial models in order to determine if both a

733 general factor and specific sub-factors contribute to a biopsychosocial model of SWB, we did not

734 use Measurement Invariance analyses (using, for example, SEM). We suggest that future studies

735 use Measurement Invariance analyses to determine whether structural factor loadings, intercepts,

736 residual variances and model fit indexes are similarly/equivalent across multiple

737 populations/groups (e.g., cultures, ethnicities, countries, age, and gender) and/or over different

738 occasions. Another limitation is that we tested convergent and discriminant validity only between

739 the scales of the model, so we recommend that future studies should test convergent and

740 discriminant validity using the scores of these scales that where generated by the bifactor model

741 and other factors that are important for subjective well-being (e.g., personality, psychological well-

742 being).

743 Although the fit indexes of the bifactor model were better, compared with all the other

744 models, they were still not excellent. More theoretical and practical evidence is required to clarify

745 the psychometric properties of SWLS, HILS, PA, and NA when they are suggested as part of a

746 whole or a biopsychosocial model of subjective well-being. For example, the social construct

747 proposed here, harmony in life, is operationalized with a relatively new instrument that needs

748 further development (see for example Kjell \& Diener, 2020). Furthermore, the concept of a social

749 part of subjective well-being needs further discussion. One could argue that the concept of

750 resilience, the ability to cope successfully in adverse circumstances, might be a plausible contender

751 for the title of the social part of subjective well-being. Although we agree with this to some point,

752 we argue that resilience is rather a combination of different personality traits (cf. Eley, Cloninger,

753 Walters, Laurence, Synnott, \& Wilkinson, 2013), rather than a construct equal to life satisfaction

754 or positive and negative affect that are judgements of biological emotional reactions and 
755 judgements of one's life in relation to a psychological self-imposed ideal, respectively. In contrast,

756 harmony is a construct that indicates how people think about their life in relation to the self, others,

757 and the world around them - a process that involves acceptance and adaptation in order to bring

758 balance to one's life. Since our results suggest a clear tendency for multidimensionality, rather

759 than unidimensionality, further studies should replicate our findings using bifactor analysis, but

760 also Multidimensional Item Response Theory. Furthermore, we only used the most common

761 instrument to operationalize each subjective well-being component. There are however different

762 well-validated scales that can be used in future studies (for a compilation see, for example, Lopez

$763 \&$ Snyder, 2004). For instance, although it has been very widely applied, the PANAS may not be

764 such a good measure for operationalizing the affective component of a biopsychosocial model of

765 subjective well-being, since it showed evidence of bad fit in the unidimensional models (see for

766 example Rice \& Shorey-Fennell, 2020, who suggest the Scale of Positive and Negative

767 Experiences developed by Diener et al., 2010). That being said, we suggest that the bad fit of the

768 PANAS only reflects the multidimensional nature of affect, as measured by the PANAS. This

769 suggestion was partially confirmed by the bifactor model in which PA and NA showed both clear

770 general and specific tendencies.

One important caveat here is that most of the times, subjective well-being is measured

through self-reports or having people giving their recollection of emotions, life satisfaction and even harmony in life. As such, all components are then cognitive in nature and should therefore

be seen as parts of a cognitive whole that is influenced by internal states and traits and external situations (see Schwartz \& Strack, 1999). Nevertheless, despite the fact that the components are psychological representations, they are also distinctive within a biopsychosocial perspective. The

777 affective component, for example, is a psychological characteristic representing the emotional 
778

779

780

781

782

783

784

785

786

787

788

789

790

791

792

793

794

795

796

797

798

799

800

experience of a person; an experience that depends on their nervous system, which is biological in nature. Likewise, harmony in life is also a cognitive phenomenon that is an evaluation of one's inner state and social interactions between the self, others and the world around. We suggest that the lack of a biopsychosocial perspective probably explains the confusion in the literature with regard to harmony being seen as a complement to the cognitive part of subjective well-being and not as an own part of the whole subjective well-being concept. Something that was clearly showed in our analyses. In other words, the overarching biopsychosocial model of subjective well-being proposed here is purely cognitive in nature. Since subjective well-being is cognitive in nature, at least as measured in most of the literature, we propose that the biological part of this cognitive whole is affect, the psychological part is life satisfaction, and the social part is harmony in life. By measuring all three parts, we get a holistic view of what makes people flourish and resilient. After all, besides optimal conditions for human potential (i.e., flourishing), we need also to understand what makes people adapt and remain healthy, happy, and fulfilled in the face of current world challenges (Cloninger, 2013).

\section{References}

Adler, M. G., \& Fagley, N. S. (2005). Appreciation: Individual differences in finding value and meaning as a unique predictor of subjective well-being. Journal of personality, 73(1), 79-7 114.

Bollen, K. A. (1989). Structural equations with latent variables. New York: John Wiley \& Sons, Inc.

Bornovalova, M. A., Choate, A. M., Fatimah, H., Petersen, K. J., \& Wiernik, B. M. (2020). Appropriate Use of Bifactor Analysis in Psychopathology Research: Appreciating Benefits and Limitations. Biological Psychiatry. DOI: 10.1016/j.biopsych.2020.01.013. 
801 Browne, M.W., \& Cudeck, R. (1993). Alternative ways of assessing model fit. In: Bollen K. A., 802 Long JS, eds. Testing structural equation models. Newbury Park: Sage, 136-162.

803

804

805

806

807

808

809

810

811

812

813

814

815

816

817

818

819

820

821

Buhrmester, M., Kwang, T., \& Gosling, S. D. (2011). Amazon's Mechanical Turk: A new source of inexpensive, yet high-quality, data?. Perspectives on psychological science, 6(1), 3-5.

Cloninger, C. R. (2004). Feeling good: the science of well-being. Oxford University Press.

Cloninger, C. R. (2013a). What Makes People Healthy, Happy, and Fulfilled in the Face of Current World Challenges? Mens Sana Monographs, 11, 16-24. doi: 10.4103/09731229.109288.

Cloninger, C. R. (2013b). The Importance of Ternary Awareness for Overcoming Inadequacies of Contemporary Psychiatry. Revista Psycologica Clinica, 40, 110-113

Cloninger, C. R., \& Cloninger, K. M. (2011a). Person-centered Therapeutics. The International Journal of Person Centered Medicine, 1 (1), 43-52.

Cloninger, C. R., \& Cloninger, K. M. (2011b). Development of Instruments and Evaluative Procedures on Contributors to Illness and Health. The International Journal of Person Centered Medicine, 1, 446-455.

Cloninger, C. R., \& Garcia, D. (2015). The Heritability and Development of Positive Affect and Emotionality. In M. Pluess (Ed.), Genetics of Psychological Well-Being - The Role of Heritability and Genetics in Positive Psychology (97-113). New York: Oxford University Press.

Cloninger, C. R., Salloum, I. M., \& Mezzich, J. E. (2012). The Dynamic Origins of Positive Health and Wellbeing. The International Journal of Person Centered Medicine, 2 (2), 179-187.

Comrey, A., \& Lee, H. (1992). A first course in factor analysis. Hillsdale, NJ: Erlbaum. 
822 Crawford, J. R., \& Henry, J. D. (2004). The Positive and Negative Affect Schedule (PANAS):

823 Construct validity, measurement properties and normative data in a large non-clinical 824 sample. British journal of clinical psychology, 43(3), 245-265.

825 Delle Fave, A., Brdar, I., Freire, T., Vella-Brodrick, D., \& Wissing, M. P. (2011). The eudaimonic 826 and hedonic components of happiness: Qualitative and quantitative findings. Social $827 \quad$ Indicators Research, 100(2), 185-207.

828 Diener, E. (1984). Subjective well-being. Psychological bulletin, 95(3), 542-575.

829 Diener, E. D., Emmons, R. A., Larsen, R. J., \& Griffin, S. (1985). The satisfaction with life scale. Journal of personality assessment, 49(1), 71-75

Diener, E., \& Diener, C. (1996). Most people are happy. Psychological science, 7(3), 181-185.

Diener, E., Inglehart, R., \& Tay, L. (2013). Theory and validity of life satisfaction scales. Social Indicators Research, 112(3), 497-527.

Diener, E., Lucas, R., Helliwell, J. F., Helliwell, J., \& Schimmack, U. (2009). Well-being for public policy. Series in Positive Psychology.

Diener, E., Lucas, R. E., \& Oishi, S. (2018). Advances and open questions in the science of subjective well-being. Collabra. Psychology, 4(1).

Diener, E., \& Seligman, M. E. (2002). Very happy people. Psychological science, 13(1), 81-84.

Diener, E., Wirtz, D., Tov, W., Kim-Prieto, C., Choi, D., Oishi, S., \& Biswas-Diener, R. (2010). New well-being measures: Short scales to assess flourishing and positive and negative feelings. Social Indicators Research, 97, 143-156.

Delle Fave, A., Brdar, I., Freire, T., Vella-Brodrick, D., \& Wissing, M. P. (2011). The eudaimonic and hedonic components of happiness: Qualitative and quantitative findings. Social Indicators Research, 100(2), 185-207. 
845 Eid, M., \& Larsen, R. J. (Eds.) (2008). The science of subjective well-being. New York: Guilford $846 \quad$ Press.

847 Eley, D., Cloninger, C., Walters, L., Laurence, C., Synnott, R., \& Wilkinson, D. (2013). The 848 relationship between resilience and personality traits in doctors: Implications for enhancing 849 well being. PeerJ, 1, e216.

850 Engel, G. L. (1980). The Clinical Application of the Biopsychosocial Model. The American 851 Journal of Psychiatry, 137, 535-544.

852 Fujita, F., \& Diener, E. (2005). Life Satisfaction Set Point: Stability and Change. Journal of 853

Personality and Social Psychology, 88, 158-164. DOI: 10.1037/0022-3514.88.1.158.

854 855

856

857

858

859

860

861

862

863

864

865

Glaesmer, H., Grande, G., Braehler, E., \& Roth, M. (2011). The German version of the Satisfaction with Life Scale (SWLS): Psychometric properties, validity, and population-based norms. European Journal of Psychological Assessment, 27, 127-132. DOI: 10.1027/10155759/a000058.

Horn, J. L. (1965). A rationale and test for the number of factors in factor analysis. Psychometrika, $30,179-85$.

Josefsson K, Cloninger CR, Hintsanen M, Jokela M, Pulkki-Råback L, Keltikangas-Järvinen L. Associations of personality profiles with various aspects of well-being: a population-based study. J Affect Disord. 2011;133:265-73.

Kenny, D. A., Kaniskan, B., \& Mccoach, B. (2015). The Performance of RMSEA in Models With Small Degrees of Freedom. Sociological Methods \& Research, 44, 486-507. DOI: 10.1177/0049124114543236. 
866 Kercher, K. (1992). Assessing subjective well-being in the old-old: The PANAS as a measure of 867 orthogonal dimensions of positive and negative affect. Research on Aging, 14(2), 131868 11168.

869

870

871 872

Killgore, W. D. S. (2000). Evidence for a third factor on the Positive and Negative Affect Schedule in a college student sample. Perceptual and Motor Skills, 90(1), 147-152.

Kline RB. (2010). Principles and practice of structural equation modeling. 3rd edition. New York: Guilford Press.

Kjell, O. N. E., Daukantaitė, D., Hefferon, K., \& Sikström, S. (2016). The harmony in life scale complements the satisfaction with life scale: expanding the conceptualization of the cognitive component of subjective well-being. Social Indicators Research, 126(2), 893-919

Kjell, O. N. E., \& Diener, E. (2020). Abbreviated Three-Item Versions of the Satisfaction with Life Scale and the Harmony in Life Scale Yield as Strong Psychometric Properties as the Original Scales. Journal of Personality Assessment. DOI: 10.1080/00223891.2020.1737093.

Li, C. (2008). The philosophy of harmony in classical Confucianism. Philosophy compass, 3(3), 423-435.

Lopez, S. J., \& Snyder, C. R. (2003). Positive Psychological Assessment: A Handbook of Models and Measures. American Psychological Association.

Lucas, R. E., Clark, A. E., Georgellis, Y., \& Diener, E. (2003). Re-examining adaptation and the setpoint model of happiness: Reactions to changes in marital status. Journal of Personality and Social Psychology, 84, 527-539.

Lyubomirsky, S. (2008). The how of happiness: A scientific approach to getting the life you want. Penguin. 
888 Mackinnon, A., Jorm, A. F., Christensen, H., Korten, A. E., Jacomb, P. A., \& Rodgers, B. (1999).

889 A short form of the Positive and Negative Affect Schedule: Evaluation of factorial.

890 Maruyama, G. (1997). Basics of structural equation modeling. Thousand Oaks, CA: Sage

$891 \quad$ Publications.

892 Mehrabian, A. (1997). Comparison of the PAD and PANAS as models for describing emotions and for differentiating anxiety from depression. Journal of psychopathology and behavioral

894 assessment, 19(4), 331-357.

Moksnes, U., \& Løhre, A., Lillefjell, M., Byrne, D., \& Haugan, G. (2014). The Association Between School Stress, Life Satisfaction and Depressive Symptoms in Adolescents: Life Satisfaction as a Potential Mediator. Social Indicators Research. 125. DOI: 10.1007/s11205014-0842-0.

Nima, A. A., Cloninger, K. M., Persson, B. N., Sikström, S., \& Garcia, D. (2020). Validation of Subjective Well-Being Measures using Item Response Theory. Frontiers in Psychology, 10: 3016. DOI: $10.3389 /$ fpsyg.2019.03036.

Oishi, S. (2006). The concept of life satisfaction across cultures: An IRT analysis. Journal of 903 Research in Personality, 40(4), 411-423.

904

905

906

907

908

909

Oishi, S. (2007). The application of structural equation modeling and item response theory to cross-cultural positive psychology research. In A. D. Ong \& M. H. M. van Dulmen (Eds.), Series in positive psychology. Oxford handbook of methods in positive psychology (pp. 12 126-138). New York, NY, US: Oxford University Press.

Ortuño-Sierra, J., Aritio-Solana, R., Chocarro de Luis, E., Navaridas Nalda F., \& Fonseca-Pedrero, E. (2019) Subjective well-being in adolescence: New psychometric evidences on the 
910

911

912 Ortuño-Sierra, J., Bañuelos, M., Pérez de Albéniz, A., Molina, B. L., Fonseca-Pedrero, E. (2019).

913 The study of Positive and Negative Affect in children and adolescents: New advances in a 914 Spanish version of the PANAS. PLoS ONE 14(8): e0221696. DOI: $915 \quad$ 10.1371/journal.pone.0221696.

916 Ortuño-Sierra, J., Santarén Rosell, M., perez-albeniz, A., \& Fonseca-Pedrero, E. (2015). 917 Dimensional Structure of the Spanish Version of the Positive and Negative Affect Schedule 918 (PANAS) in Adolescents and Young Adults. Psychological assessment, 27, e1-e9. DOI: 919

satisfaction with life scale. European Journal of Developmental Psychology, 16, 236-244. DOI: $10.1080 / 17405629.2017 .1360179$. $10.1037 /$ pas0000107.

Quinn, H. (2014). Bifactor Models, Explained Common Variance (ECV), and the Usefulness of Scores from Unidimensional Item Response Theory Analyses

Peterson, C., \& Seligman, M. E. P. (2004). Character Strengths and Virtues: A Handbook and Classification. New York: Oxford University Press.

Pavot, W. (2018). The cornerstone of research on subjective well-being: Valid assessment methodology. In: Diener, E., Oishi, S., \& Tay, L. (Eds.), Handbook of Well-Being. Noba Scholar Handbook Series: Subjective Well-Being. Salt Lake City, UT: DEF Publishers.

Pavot, W., \& Diener, E. (1993). Review of the satisfaction with life scale. Psychological Assessments, 5, 164-172.

Pavot, W., \& Diener, E. (2008). The satisfaction with life scale and the emerging construct of life satisfaction. The journal of positive psychology, 3(2), 137-152. 
931 Pires, P., Filgueiras, A., Ribas, R., \& Santana, C. (2013). Positive and negative affect schedule:

932 psychometric properties for the Brazilian Portuguese version. The Spanish journal of 933 psychology.

934 Reise, S. P., Bonifay, W. E., \& Haviland, M. G. (2013). Scoring and modeling psychological 935 measures in the presence of multidimensionality. Journal of Personality Assessment, 95, 936 129-140.

937 Reise, S.P., Bonifay, W., \& Haviland, M.G. (2018). Bifactor modeling and the evaluation of scale 938 scores. In P. Irwing, T. Booth, \& D. J. Hughes (Eds.). The Wiley Handbook of Psychometric 939 Testing: A multidisciplinary reference on survey, scale and test development, 1-2, 677-706. 940 Hoboken, NJ, EUA: John Wiley \& Sons.

941 Rice, S. P. M., \& Shorey-Fennell, B. R. (2020). Comparing the Psychometric Properties of 942 Common Measures of Positive and Negative Emotional Experiences: Implications for the 943 Assessment of Subjective Wellbeing. Journal of Well-Being Assessment. DOI: $10.1007 / \mathrm{s} 41543-020-00025-1$

Rodriguez, A., Reise, S. P., \& Haviland, M. G. (2016b). Evaluating bifactor models Calculating 946 and interpreting statistical indices. Psychological Methods, 21, 137-150.

Russell, J.A. (1980). A circumplex model of affect. Journal of Personality and Social Psychology, Vol 39(6), Dec, 1161-1178

Russell, J.A and Feldman Barrett, L. (1999) Core affect, prototypical emotional episodes, 950 and other things called emotion: dissecting the elephant. Journal of Personality and Social Psychology 76:805-819 DOI 10.1037/0022-3514.76.5.805.

952 Sanmartín, R., Inglés, C. J., Vicent, M., Gonzálvez, C., Díaz-Herrero, Á., et al. (2018). Positive and 953 negative affect as predictors of social functioning in Spanish children 
Positive and negative affect as predictors of social functioning in Spanish children. PLOS ONE 13(8): e0201698. DOI: 10.1371/journal.pone.0201698.

956 957

Satorra, A., \& Bentler, P. M. (2001). A scaled difference chi-square test statistic for moment structure analysis. Psychometrika, 66, 507-514.

Schwartz, N., \& Strack, F. (1999). Reports of subjective well-being: Judgmental process and their methodological implications. In D. Kahneman, E. Diener, \& N. Schwarz (Eds.), Well-being: The foundations of hedonic psychology (pp. 61-84). New York: Russell Sage Found.

Senécal, C., Nouwen, A., \& White, D. (2000). Motivation and dietary self-care in adults with diabetes: are self-efficacy and autonomous self-regulation complementary or competing constructs?. Health psychology, 19(5), 452-457.

Singh, K., Mitra, S., \& Khanna, P. (2016). Psychometric Properties of Hindi Version of Peace of Mind, Harmony in Life and Sat-Chit-Ananda Scales. Indian Journal of Clinical Psychology, $43(1), 58-64$.

Steger, M. F., Frazier, P., Oishi, S., \& Kaler, M. (2006). The meaning in life questionnaire: Assessing the presence of and search for meaning in life. Journal of counseling psychology, 53(1), 80-93.

Stucky, B. D., \& Edelen, M. O. (2014). Using hierarchical IRT models to create unidimensional measures from multidimensional data. In S. P. Reise \& D. A. Revicki (Eds.), Handbook of item response theory modeling: Applications to typical performance assessment (pp. 183206). New York, NY: Routledge/Taylor \& Francis Group.

Tabachnick, B. G. \& Fidell, L. S. (2007). Using multivariate statistics (5th, internationaled). Boston: Pearson Education. 
976 Terraciano, A., McCrae, R. R., \& Costa, P. T. Jr. (2003). Factorial and construct validity of the 977 Italian Positive and Negative Affect Schedule (PANAS). European Journal of Psychological $978 \quad$ Assessment, 19(2), 131-141

979 Thompson, B. (2004). Exploratory and confirmatory factor analysis: Understanding concepts and 980 applications. American Psychological Association. DOI: doi.org/10.1037/10694-000.

981 Thompson, E. R. (2007). Development and validation of an internationally reliable short-form of 982 the positive and negative affect schedule (PANAS). Journal of cross-cultural psychology, $983 \quad 38(2), 227-242$.

984 Watson, D., Clark, L. A., \& Tellegen, A. (1988). Development and validation of brief measures of 985 positive and negative affect: the PANAS scales. Journal of personality and social $986 \quad$ psychology, 54(6), 1063-1070.

987 Watson, D., \& Clark, L. A. (1994). The PANAS-X: Manual for the Positive Affect and 12 Negative 988 Affect Schedule — expanded form. Iowa City: University of Iowa.

989 WHO, 2001. Mental Health: New Understanding, New Hope. World Health Organization, $990 \quad$ Geneva.

991 Zinbarg, R. E., Revelle, W., and Yovel, I. (2007). Estimating wh for structures containing two 992 group factors: perils and prospects. Appl. Psychol. Meas. 31, 135-157. doi: $993 \quad 10.1177 / 0146621606291558$

994 Zwir, I., Arnedo, J., Del-Val, C., Pulkki-Raback, L., Konte, B., Yang, S. S., . . Cloninger, C. R. 995 (2018a). Uncovering the com- plex genetics of human character. Molecular Psychiatry. 996 doi:10.1038/s41380-018-0263-6 
997 Zwir, I., Arnedo, J., Del-Val, C., Pulkki-Raback, L., Konte, B., Yang, S. S., . . Cloninger, C. R. 998 (2018b). Uncovering the com- plex genetics of human temperament. Molecular Psychiatry. 999 doi: $10.1038 / \mathrm{s} 41380-018-0264-5$

1000 Zwir, I., Arnedo, J., Del-Val, C., Pulkki-Råback, L., Konte, B., Yang, S. S., . . Cloninger, C. R. 1001 (2019). Three genetic-environmental networks for human personality. Molecular Psychiatry. 1002 doi: 10.1038/s41380-019-0579-x. 
Figure 1

Structural equation model of bifactor model of SWBS and its specific subscales (SWLS, HILS, NA and PA).

Structural equation model of bifactor model of SWBS and its specific subscales (SWLS, HILS, NA and PA). All paths (from SWBS to each item, and from specific subscales to their items) and their standardized parameter estimates.

Note: Chi-square value $\left(\chi^{2}=1881.49, \mathrm{df}=401, p<.001\right)$, Satorra Bentler $\chi^{2}\left(S-B \chi^{2}=1419.90, d f=401, p\right.$ $<.001), \mathrm{CFI}=.91, \mathrm{TLI}=.90$ and RMSEA $=.07$. RMSEA, CFI, and TLI goodness-of-fit statistics are computed using the Satorra-Bentler scaled chi-squared statistic $(N=527)$.

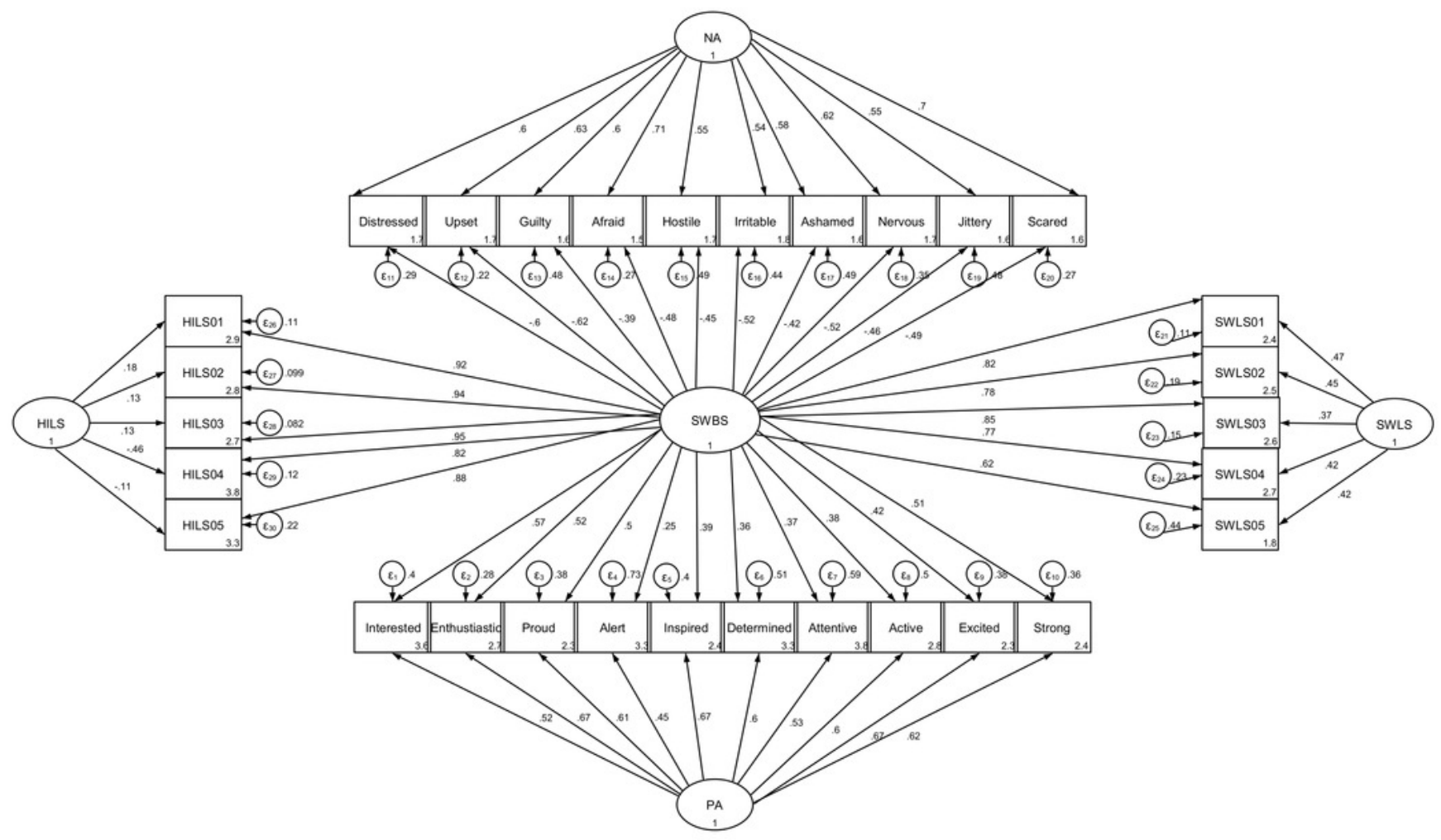




\section{Table $\mathbf{1}$ (on next page)}

Standardized loadings factor of bifactor confirmatory factor analysis for the general latent trait and its specific latent traits.

Standardized loadings factor of bifactor confirmatory factor analysis for the general latent trait (Subjective Well-Being, SWBS) and its specific latent traits (Satisfaction with Life, SWLS, Harmony in Life, HILS, Positive Affect, PA, and Negative Affect, NA). 
1 Table 1: Standardized loadings factor of bifactor confirmatory factor analysis for the general latent 2 trait (Subjective Well-Being, SWBS) and its specific latent traits (Satisfaction with Life, SWLS, 3 Harmony in Life, HILS, Positive Affect, PA, and Negative Affect, NA). $N=527$.

\begin{tabular}{|c|c|c|c|c|c|c|c|c|}
\hline Items & SWBS & SWLS & HILS & PA & NA & h2 & $\mathbf{u 2}$ & p2 \\
\hline In most ways my life is close to my ideal. & 0.82 & 0.47 & & & & 0.89 & 0.11 & 0.75 \\
\hline The conditions of my life are excellent. & 0.78 & 0.45 & & & & 0.81 & 0.19 & 0.75 \\
\hline I am satisfied with my life. & 0.85 & 0.37 & & & & 0.86 & 0.14 & 0.84 \\
\hline $\begin{array}{l}\text { So far I have gotten the important things I } \\
\text { want in life. }\end{array}$ & 0.77 & 0.42 & & & & 0.77 & 0.23 & 0.77 \\
\hline $\begin{array}{l}\text { If I could live my life over, I would change } \\
\text { almost nothing. }\end{array}$ & 0.62 & 0.42 & & & & 0.56 & 0.44 & 0.69 \\
\hline My lifestyle allows me to be in harmony. & 0.92 & & 0.18 & & & 0.88 & 0.12 & 0.96 \\
\hline Most aspects of my life are in balance. & 0.94 & & 0.13 & & & 0.90 & 0.10 & 0.98 \\
\hline I am in harmony. & 0.96 & & 0.13 & & & 0.94 & 0.06 & 0.98 \\
\hline I accept the various conditions of my life. & 0.82 & & -0.46 & & & 0.88 & 0.12 & 0.76 \\
\hline I fit in well with my surroundings. & 0.88 & & -0.11 & & & 0.79 & 0.21 & 0.98 \\
\hline Interested & 0.57 & & & 0.52 & & 0.60 & 0.40 & 0.55 \\
\hline Enthustiastic & 0.52 & & & 0.67 & & 0.72 & 0.28 & 0.38 \\
\hline Proud & 0.50 & & & 0.61 & & 0.62 & 0.38 & 0.40 \\
\hline Alert & 0.25 & & & 0.45 & & 0.27 & 0.74 & 0.24 \\
\hline Inspired & 0.39 & & & 0.67 & & 0.60 & 0.40 & 0.25 \\
\hline Determined & 0.36 & & & 0.60 & & 0.49 & 0.51 & 0.26 \\
\hline Attentive & 0.37 & & & 0.53 & & 0.42 & 0.58 & 0.33 \\
\hline Active & 0.38 & & & 0.60 & & 0.50 & 0.50 & 0.29 \\
\hline Excited & 0.42 & & & 0.67 & & 0.63 & 0.37 & 0.28 \\
\hline Strong & 0.51 & & & 0.62 & & 0.64 & 0.36 & 0.40 \\
\hline Distressed & 0.60 & & & & -0.60 & 0.72 & 0.28 & 0.50 \\
\hline Upset & 0.62 & & & & -0.63 & 0.78 & 0.22 & 0.49 \\
\hline Guilty & 0.39 & & & & -0.60 & 0.51 & 0.49 & 0.30 \\
\hline Afraid & 0.48 & & & & -0.71 & 0.73 & 0.27 & 0.31 \\
\hline Hostile & 0.45 & & & & -0.55 & 0.51 & 0.50 & 0.40 \\
\hline Irritable & 0.52 & & & & -0.54 & 0.56 & 0.44 & 0.48 \\
\hline Ashamed & 0.42 & & & & -0.58 & 0.51 & 0.49 & 0.34 \\
\hline Nervous & 0.51 & & & & -0.62 & 0.64 & 0.36 & 0.40 \\
\hline Jittery & 0.46 & & & & -0.55 & 0.51 & 0.49 & 0.41 \\
\hline Scared & 0.49 & & & & -0.70 & 0.73 & 0.27 & 0.33 \\
\hline Omega-total ( $\square$ Total) & 0.79 & & & & & & & \\
\hline Omega Hierarchical ( $\square H$ ) & 0.64 & & & & & & & \\
\hline Omega subscale ( $\square S$ ) & & 0.94 & 0.98 & 0.72 & 0.81 & & & \\
\hline Omega hirerarchial subscale ( $\square H S$ ) & & 0.22 & 0.00 & 0.48 & 0.49 & & & \\
\hline Omega general for subscale & & 0,72 & 0,98 & 0,25 & 0,32 & & & \\
\hline ECV & 0.57 & & & & & & & \\
\hline
\end{tabular}


Eigenvalues $\begin{array}{lllll}11.47 & 0.91 & 0.29 & 3.58 & 3.73\end{array}$

4 Note. $\mathrm{h} 2=$ communalities, $\mathrm{u} 2=$ error variance (uniqueness), $\mathrm{p} 2=$ item explained common

5 variance (I-ECV), Raw items of the NA are Reversed. 


\section{Table 2 (on next page)}

Descriptive statistics for all the scores using the different methods applied in the Study.

Descriptive statistics for all the scores using the different methods applied in the Study $(N=$ 527). 
1 Table 2. Descriptive statistics for all the scores using the different methods applied in the Study $2(N=527)$.

\begin{tabular}{|c|c|c|c|c|c|c|}
\hline Variables & Minimum & Maximum & Mean & $S D$ & Skewness & Kurtosis \\
\hline SWLS Traditional average & 1.00 & 7.00 & 4.56 & 1.72 & -0.60 & -0.71 \\
\hline SWLS Unidimensional Model & -3.68 & 2.36 & 0.00 & 1.75 & -0.69 & -0.64 \\
\hline SWLS Correlated Model & -3.88 & 2.41 & 0.00 & 1.75 & -0.71 & -0.57 \\
\hline SWLS Higher Order Factor & -3.88 & 2.39 & 0.00 & 1.75 & -0.71 & -0.56 \\
\hline SWLS Bifactor & -4.11 & 2.51 & 0.00 & 0.79 & -1.12 & 3.43 \\
\hline HILS Traditional average & 1.00 & 7.00 & 5.02 & 1.50 & -0.90 & 0.10 \\
\hline HILS Unidimensional Model & -3.77 & 2.02 & 0.00 & 1.55 & -0.84 & -0.20 \\
\hline HILS Correlated Model & -3.88 & 2.07 & 0.00 & 1.55 & -0.84 & -0.19 \\
\hline HILS Higher Order Factor & -3.86 & 2.08 & 0.00 & 1.55 & -0.83 & -0.20 \\
\hline HILS Bifactor & -3.34 & 3.36 & 0.00 & 0.85 & -0.26 & 1.85 \\
\hline PA Traditional average & 1.00 & 5.00 & 3.31 & 0.90 & -0.19 & -0.47 \\
\hline PA Unidimensional Model & -1.75 & 1.34 & 0.00 & 0.72 & -0.14 & -0.60 \\
\hline PA Correlated Model & -2.55 & 1.93 & 0.00 & 1.02 & -0.16 & -0.60 \\
\hline PA Higher Order Factor & -2.55 & 1.93 & 0.00 & 1.02 & -0.16 & -0.59 \\
\hline PABifactor & -2.95 & 2.62 & 0.00 & 0.94 & -0.07 & -0.22 \\
\hline NA Traditional verage & 1.00 & 5.00 & 1.68 & 0.83 & 1.56 & 2.06 \\
\hline NA Unidimensional Model & -0.75 & 3.53 & 0.00 & 0.92 & 1.52 & 1.89 \\
\hline NA Correlated Model & -0.72 & 3.22 & 0.00 & 0.84 & 1.50 & 1.82 \\
\hline NA Higher Order Factor & -3.22 & 0.73 & 0.00 & 0.84 & -1.50 & 1.81 \\
\hline NA Bifactor & -2.86 & 3.64 & 0.00 & 0.95 & 0.96 & 1.60 \\
\hline SWBS Traditional average & -2.07 & 1.11 & 0.00 & 0.66 & -0.74 & 0.05 \\
\hline SWBS Unidimensional Model & -4.59 & 2.43 & 0.00 & 1.62 & -0.80 & -0.12 \\
\hline SWBS Higher Order Factor & -1.59 & 0.88 & 0.00 & 0.62 & -0.80 & -0.23 \\
\hline SWBS Bifactor & -2.65 & 1.34 & 0.00 & 0.99 & -0.87 & -0.02 \\
\hline
\end{tabular}

3 Note: Subjective Well-Being (SWBS) traditional average $=$ A simple average of standardized

4 scores of 30 items including reversed items of Negative Affect (NA), Satisfaction with Life Scale

5 (SWLS) traditional average (simple average of raw scores of 5 items), Harmony in Life Scale

6 (HILS) traditional average (simple average of raw scores of 5 items), NA traditional average

7 (simple average of raw scores of 10 five items), Positive Affect (PA) traditional average (simple 
8 average of raw scores of 10 items). Reversed items of NA were included in SWBS Unidimensional 9 model, Higher order factor and Bifactor. 


\section{Table 3(on next page)}

Correlations of SWBS and its subscales via different models in the study.

Correlations of SWBS and its subscales via different models in the study ( $\mathrm{N}=527)$. 
1 Table 3. Correlations of SWBS and its subscales via different models in the study $(N=527)$.

\begin{tabular}{llllll}
\hline Variables & 1 & 2 & 3 & 4 & 5 \\
\hline SWLS Traditional average 1 & & & & \\
SWLS Unidimensional Model 2 & $.991^{* *}$ & & & \\
SWLS Correlated Model 3 & $.987^{* *}$ & $.997^{* *}$ & & \\
SWLS Higher Order factor 4 & $.987^{* *}$ & $.997^{* *}$ & $\mathbf{1 . 0 0 ^ { * * }}$ & \\
SWLS Bifactor 5 & $.535^{* *}$ & $.527^{* *}$ & $.461^{* *}$ & $.460^{* *}$ & \\
\cline { 2 - 6 } & 1 & 2 & 3 & 4 & 5
\end{tabular}

HILS Traditional average 1

\begin{tabular}{llllll} 
HILS Unidimensional Model 2 & $.991^{* *}$ & & & \\
HILS Correlated Model 3 & $.991^{* *}$ & $\mathbf{. 9 9 8}^{* *}$ & & \\
HILS Higher Order Factor 4 & $.992^{* *}$ & $.998^{* *}$ & $\mathbf{1 . 0 0 * *}$ & \\
HILS Bifactor 5 & -0.012 & $.107^{*}$ & $.095^{*}$ & $.094^{*}$ & \\
\cline { 2 - 6 } & 1 & 2 & 3 & 4 & 5
\end{tabular}

PA Traditional average 1

PA Unidimensional Model $2 \quad .994^{* * *}$

PA Correlated Model 3

\begin{tabular}{|c|c|c|c|}
\hline $.992^{* * *}$ & $.999^{* *}$ & & \\
\hline $.992^{* *}$ & $.999^{* * *}$ & $0.99 * *$ & \\
\hline $.830^{* *}$ & $.826^{* *}$ & $.796^{* *}$ & $.796^{* *}$ \\
\hline 1 & 2 & 3 & 4 \\
\hline
\end{tabular}

NA Traditional average 1

NA Unidimensional Model 2 $.996^{* *}$

NA Correlated Model 3

\begin{tabular}{|c|c|c|c|}
\hline $.994^{* *}$ & $.999^{* *}$ & & \\
\hline$-.994^{* *}$ & $-.999^{* *}$ & $-1.000^{* *}$ & \\
\hline $.790^{* *}$ & $.789^{* *}$ & $.762^{* *}$ & $-.763^{* *}$ \\
\hline 1 & 2 & 3 & 4 \\
\hline
\end{tabular}

SWBS Traditional average 1

SWBS Unidimensional Model 2

$.953^{* *}$

SWBS Higher Order Factor $3 \quad .912^{* *} \quad .992^{* * *}$

SWBS Bifactor 4

$.890^{* *} \quad .976^{* *} \quad .989^{* *}$

Note: $* p<.05, * * p<.01$, Subjective Well-Being (SWBS) traditional average $=$ A simple average of standardized scores of 30 items including reversed items of Negative Affect (NA), Satisfaction with Life Scale (SWLS) traditional average (simple average of raw scores of 5 items), Harmony in Life Scale (HILS) traditional average (simple average of raw scores of 5 items), NA traditional average (simple average of raw scores of 10 five items), Positive Affect (PA) traditional average 
7 (simple average of raw scores of 10 items). Reversed items of NA were included in SWBS

8 Unidimensional model, Higher order factor and Bifactor. 